\title{
LETTERS
}

\section{Resilience Training and Physician Well-Being}

\author{
Roy M. Poses, $M D^{7}$, Wally R. Smith, $M D^{2}$, and Russell Maulitz, MD \\ 'Brown University, Warren, RI, USA; ${ }^{2}$ Virginia Commonwealth University, Richmond, USA; ${ }^{3}$ Drexel University College of Medicine, Philadelphia, \\ USA.
}

$\mathrm{J}$ Gen Intern Med 26(11):1243

DOI: $10.1007 / \mathrm{s} 11606-011-1854-\mathrm{y}$

() Society of General Internal Medicine 2011

To the Editor:- Sood and colleagues developed a training program to increase physician resilience and reduce stress that presumably arises from "multiple demands and expectations." They did not further explicate what these were. ${ }^{1}$ Feldman's accompanying editorial noted that this training could help physicians working in "organizations that reward overwork and dissociation from human feelings and meaning at work," and who experience burnout due to "the rise of managed care and concomitant increased paperwork and other administrative demands that sap time that could be spent with patients and leave physicians with a diminished sense of autonomy and control over their work." ${ }^{2}$

We agree, but believe there needs to be more focus on the nature of the external stressors physicians face. In 2003, we noted physicians felt their core values were threatened by a dysfunctional health care system dominated by large organizations whose leadership did not share their values, and were at times ill-informed, incompetent, self-interested and even corrupt. ${ }^{3}$ In 2010, Pololi and colleagues' qualitative interviews with academic generalists included cases in which institutional leadership appeared to put revenues ahead of patient care, teaching, and research, thus forsaking the core values of physicians and academia. Some faculty complained of leaders who allegedly used deception for personal and professional gain. ${ }^{4}$ Pololi and colleagues have also presented survey data that showed at least 50\% of academic generalists felt their institutions' leadership only cared about the revenue they generated, and did not value teaching, and 30\% were afraid to speak out about leaderships' failings. ${ }^{5}$

Thus it is reasonable to hypothesize that external threats to physicians' core values due to poor leadership of increasingly large health care organizations cause stress and burnout. Would it not make more sense to try to counter these stressors directly, rather than just train physicians to be more resilient? Would increasing physician resilience not make them more accepting of what should not be acceptable?

Corresponding Author: Roy M. Poses, MD; Brown University, 16 CutlerSt., Suite 104, Warren, RI02885, USA (e-mail: roy_poses@brown. edu).

\section{REFERENCES}

1. Sood A, Prasad K, Schroeder D, Varkey P. Stress management and resilience training among Department of Medicine faculty: a pilot randomized clinical trial. J Gen Intern Med. 2011;26:858-861.

2. Feldman MD. From the Editor's desk: physician heal thyself. J Gen Intern Med. 2011;26:823.

3. Poses RM. A cautionary tale: the dysfunction of American health care. Eur J Int Med. 2003; 14:123-130.

4. Pololi L, Kern DE, Carr P, Conrad P, Knight S. The culture of academic medicine: faculty perceptions of the lack of alignment between individual and institutional values. J Gen Intern Med. 2009;24:1289-1295.

5. Pololi L, Ash A, Krupat E. Faculty values in the culture of academic medicine: findings of a national faculty survey. Annual Conference in Research in Medical Education, 2010. https://www.aamc.org/download/ 154216/data/your_career_is_more_than_your_specialty_-_246.pdf 